\title{
Evaluation of Thymus vulgaris Extract on Hippocampal Injury Induced by Transient Global Cerebral Ischemia and Reperfusion in Rat
}

\author{
Mahbubeh Setorki, ${ }^{1,}{ }^{*}$ and Sahar Mirzapoor ${ }^{1}$ \\ ${ }^{1}$ Department of Biology, Izeh Branch, Islamic Azad University, Izeh, Iran \\ "Corresponding author: Mahbubeh Setorki, Department of Biology, Izeh Branch, Islamic Azad University, Izeh, Iran. E-mail: doctor.setorgi@gmail.com
}

Received 2016 October 01; Revised 2016 December 04; Accepted 2017 April 19.

\begin{abstract}
Background: A Brief interruption of blood supply to the brain can cause significant changes in the function of central nervous system. Patients usually show cognitive, emotional and electrophysiological changes during recovery from stroke. Preliminary pharmacokinetic studies have shown that Thymus vulgaris is useful in the treatment of seizures, respiratory diseases, smooth muscular spasm and bloating.

Methods: In an experimental study, for inducing temporary acute ischemia carotid artery was closed for 60 minutes and then blood flow was restored. Thyme extract $(50,100$ and $200 \mathrm{mg} / \mathrm{kg}$ ) was injected daily after induction of ischemia. Shuttle box test was carried out for the first 4 days and rotarod test was conducted at the last day. After the rotarod test, blood samples were collected from heart and brain tissue was removed under deep anesthesia. One way-ANOVA followed by Tukey and t-paired tests were used for comparing the groups at 0.05 level of significance. All data were analyzed by using the statistical package for social sciences (SPSS-19) software. Results: In passive avoidance test, the initial latency time was significantly longer in the ischemia group compared to the control group. Administration of thyme extract into ischemic rats significantly increased second latency time and reduced MDA levels of brain cortex.
\end{abstract}

Conclusions: Our results indicated that Thymus vulgaris extract has a neuroprotective activity. Mechanisms of neuroprotective action might be associated with antioxidant activity and inhibition of oxidative stress in rat brain.

Keywords: Thymus vulgaris, Shuttle Box, Rotarod, MDA

\section{Background}

The rate of cerebral ischemia, the dominate cause of disability, is rising sharply [1]. Brain tissue is very sensitive to ischemia because of high metabolism and oxygen consumption [2]. Two cellular response occurs during ischemic injury [3].

1- Acute response: reduced energy supply and production of free radicals. Due to low brain oxygen levels anaerobic glycolysis occurs which is insufficient energy supply [4]. Reduced energy supply may lead to some harmful biochemical cascades. Free radicals and generated prostaglandins will attack membrane polyunsaturated fatty acid (PUFA) which cause damage to cellular membrane and increase its permeability. Mitochondrial respiratory chain is the main source of reactive oxygen species (ROS) and its destruction can lead to necrotic cell death. Endothelial cell death is responsible for the bloodbrain barrier breakdown and cerebral edema $[5,6]$.

2- Delayed response to ischemia: a second wave of cell death in response to ischemia may occur through release of inflammatory mediators. During ischemia activated microglia will produce inflammatory cytokines such as TNF $\alpha$ (tumor necrosis factor), IL-1 $\beta$ and cytotoxic molecules such as NO and ROS [7, 8]. Astrocytes are also able to produce inflammatory factors such as cytokines, chemokines and NOS (nitric oxide synthetase). Increased consumption of antioxidants has been shown to improve spatial learning and long term potentiation (LTP) induction in mice with Alzheimer's disease $[9,10]$.

From the beginning of human existence, humans identified and used medicinal plant for treatment of various diseases. Unlike synthetic drugs, drugs derived from herbal medicine are natural. They play an important role in improving physiological function and treating disorders [11].

Thyme (Thymus vulgaris) has been used in traditional medicine for centuries and recorded in world major pharmacopoeia as an effective herbal medicine [12]. The leaves of this plant contain $1 \%-2.5 \%$ essential oil. Thymol $(20 \%$ - 55\%) and Carvacrol (1\% - 10\%) are the main components of essential oil. Other components include linalool, pcymene and $\alpha$-pinene. Thymus vulgaris is a medicinal plant of the mint family. This plant is a short and ramous shrub which has thin and mutual leaves. Thymol is an active ingredient of plant that stimulates brain and improves memory. Thyme tea helps for strengthening the mind, disinfect- 
ing the respiratory tract and sinuses and treating asthma and bronchitis. Ancient Greek physicians recommended thyme tea for preventing and treating brain disorders [13].

Oxidative stress is associated with increased production of nitric oxide and superoxide. Disruption in their production and metabolism can result in pathological damage [14]. Antioxidant compounds have been investigated in a number of in vitro and in vivo experimental models, some of them also investigated in clinical trials [1517].

Aim of this study was to evaluate the neuroprotective effect of thyme extract on learning, memory and biochemical factors fallowing cerebral ischemia in rats.

\section{Methods}

\subsection{Preparation of the Extract:}

Thymus vulgaris were purchased from medicinal herbs store. $25 \mathrm{~g}$ of milled plant was placed in $70 \%$ ethanol for 72 hours. The solution was stirred several times per day. The mixture was then filtered and dried. The dried residue was dissolved in water and stored at $4^{\circ} \mathrm{C}$ until use [18].

\subsection{Experimental Animal}

In an experimental study, 42 male Wistar rats (mean weight: 250 - $300 \mathrm{~g}$ ) were purchased from the animal center of Ahwaz university and housed in stainless steel cages in a ventilated animal room. They were kept at a temperature of $22 \pm 2{ }^{\circ} \mathrm{C}$ under 12 hours light/12 hours dark cycle with free access to food and water. All animal handling and manipulation procedures were performed according to the guideline of the animal welfare act and the experimental protocols were approved by the office of research ethics committee of university of Ahwaz. Rats were divided randomly into 6 groups, each group consist of seven animals:

Control group $(n=7)$ : Rats received only distilled water without any surgical operation and drug treatment

Sham group $(n=7)$ : Rats underwent surgery without ligation of carotid arteries and received no drug treatment

Ischemic group $(n=7)$ : Rats underwent ischemia and received only distilled water

Thyme extract-treated group $(n=7)$ : Rats underwent ischemia and received thyme extract at a dose of $50 \mathrm{mg} / \mathrm{kg}$ intraperitoneally

Thyme extract-treated group $(n=7)$ : Rats underwent ischemia and received thyme extract at a dose of $100 \mathrm{mg} / \mathrm{kg}$ intraperitoneally

Thyme extract-treated group $(n=7)$ : Rats underwent ischemia and received thyme extract at a dose of $200 \mathrm{mg} / \mathrm{kg}$ intraperitoneally

\subsection{Induction of Ischemia}

Male Wistar rats were anesthetized by intraperitoneal injection of chloral hydrate $(400 \mathrm{mg} / \mathrm{kg})$. After anesthesia, a midline incision was made on the anterior region of the neck to expose carotid artery and then common carotid arteries were identified and isolated carefully from vagosympathetic nerve. For inducing of temporary acute ischemia carotid artery was closed for 60 minutes and then blood flow was restored. During the surgical procedure, body temperature was maintained at $37^{\circ} \mathrm{C}$ by a heating lamp. This surgical method produces sufficient forebrain ischemia in rats.

Thyme extract was injected daily after induction of ischemia. Shuttle box test was carried out for the first 4 days and rotarod test was conducted at the last day. After the rotarod test, blood samples were collected from heart and brain tissue was removed under deep anesthesia. After removal of the brain, hippocampus and cerebral cortex were separated on ice and used for biochemical analysis. Blood was centrifuged and serum was separated and used for biochemical analysis [14].

\subsection{Passive Avoidance Test}

Shuttle box consists of two equally sized compartments with a guillotine door. An electric light bulb illuminates one compartment while the other remains in dark. Each compartment has a metal floor designed to administer an electric shock. This test was based on the fear and performed on 4 consecutive days. At first, device was cleaned and test began. First and second days were performed for training and familiarity of the animals. During training, the animal was placed in the light chamber for 5 minutes and then guillotine door was opened, typically, the animal went to the dark chamber and stayed in there for 5 minutes. On the third day, animal was placed in the light chamber and after 20 seconds door was opened and the latency of mouse to enter into the dark chamber was recorded as initial latency (T1). When the animal entered the dark chamber, the door was lowered and a foot shock (0.1 mA, 1 second, one time) was applied through the grid floor. At the end of this interval, animal was placed in the light chamber one more and its latency to leave the chamber was recorded as second latency [14].

\subsection{Psychological Motor Coordination Tests}

Motor coordination and balance were tested using Rotarod apparatus. At first mice were placed on the rotating drum of rotarod and trained to walk. Rotarod has a rotating drum with a rotation speed of $0-40 \mathrm{rpm}$. This device has a belt and speed can be adjusted by changing its position. In this study rotating speed was $10 \mathrm{rpm}$ and grab 
was $7 \mathrm{rpm}^{2}$. Mice in each extract treated groups or control group were placed on an accelerating drum of rotarod which rotated for a maximum of 300 seconds and the time that mice maintain their balance were recorded. This was repeated three times for each mouse and their mean was calculated [19].

\subsection{Measurement of Plasma Antioxidant Capacity}

Three solutions were used for this purpose. Solution 1: $1.5 \mathrm{~mL}$ of sodium acetate and $8 \mathrm{~mL}$ of concentrated acetic acid which diluted to $5000 \mathrm{~mL}$ with distilled water. Solution 2: $270 \mathrm{mg}$ of ferric chloride 3 that diluted to a volume of $50 \mathrm{~mL}$ with distilled water. Solution 3: $47 \mathrm{mg}$ of treeazin which dissolved in $40 \mathrm{~mL}$ of HCL. Working solution was prepared from $10 \mathrm{~mL}$ of solution $1,1 \mathrm{~mL}$ of solution 2 and $1 \mathrm{~mL}$ of solution 3. 25 microliters of serum samples was added to $5.1 \mathrm{~mL}$ of working solution. The mixture was incubated at $37^{\circ} \mathrm{C}$ for 15 minute and then absorbance was measured at $593 \mathrm{~nm}$.

\subsection{Measurement of Brain Antioxidant Capacity}

The antioxidant capacity of brain was determined by measuring its ability to reduce $\mathrm{Fe}^{3+}$ to $\mathrm{Fe}^{2+}$ using ferric reducing antioxidant power (FRAP) assay. FRAP working solution was prepared by mixing $25 \mathrm{~mL}$ of acetate buffer, 2.5 $\mathrm{mL}$ of $\operatorname{TPTZ}$ (2, 4, 6-tripyridyl-s-triazine) and $2.5 \mathrm{~mL}$ of $\mathrm{FeCl}_{3}$. The brain was removed, homogenized and centrifuged at $1000 \mathrm{~g}$. After which the supernatant was used to evaluate the antioxidant power. $50 \mathrm{~mL}$ of supernatant was added to $5.1 \mathrm{~mL}$ of freshly prepared FRAP working solution. After 10 minutes, $\mathrm{Fe}^{3+}$ TPTZ complex was reduced to the ferrous $\left(\mathrm{Fe}^{2+}\right)$ form which produced an intense blue color. The absorbance of mixture was measured at $590 \mathrm{~nm}$.

\subsection{Measurement of Plasma Malondialdehyde (MDA)}

Blood samples were collected and then centrifuged at $10000 \mathrm{rpm}$ to separate plasma. 50 microliters of plasma were mixed with $50 \mu \mathrm{L}$ of $0.05 \%$ BHT, $400 \mu \mathrm{L}$ of $0.44 \mathrm{M}$ $\mathrm{H} 3 \mathrm{PO} 4$ and $100 \mu \mathrm{L}$ of TBA. After vortexing, the mixture was heated at $100^{\circ} \mathrm{C}$ for 1 hours and then cooled at 0 for 5 minutes. After that, mixture was mixed with butanol and vortexed. After centrifuging (14000 rpm for 5 minutes) the absorbance of the supernatant was measured at $532 \mathrm{~nm}$.

\subsection{Measurement of Brain Malondialdehyde (MDA)}

Brain tissue $(1 \mathrm{~g})$ was homogenized in chilled $5.2 \% \mathrm{KCL}$ at $1: 10 \mathrm{w} / \mathrm{v}$ ratio and transferred into a $20 \mathrm{~mL}$ tube. The tube was incubated for 60 minutes at $37^{\circ} \mathrm{C}$. After incubation, the suspension was mixed with $1 \mathrm{~mL}$ of $5 \%$ tetrachloroacetic acids and $1 \mathrm{~mL}$ of $67 \%$ TBA (thiobarbituric acid) and centrifuged for 15 minutes at $2000 \mathrm{rpm}$. The supernatant was transferred into a new tube and heated in water bath for 10 minutes. Then the suspension was cooled and its absorbance was measured at $535 \mathrm{~nm}$ [14].

\subsection{Measurement of Serum Nitrate Level}

Nitrate level of brain serum was estimated by the method described by Navarro et al. Measurement of nitrate is based on the reduction of nitrate to nitrite by cadmium. Samples were deproteinized using zinc sulfate and sodium hydroxide solutions. After centrifugation, the supernatant was saved and mixed with glycine buffer. Cadmium granules were activated by a $\mathrm{CuSO}_{4}$ solution in glycine buffer. Freshly activated cadmium granules were added to pretreated deproteinized serum and stirred for 10 minutes. After that time, the resulting solution was transferred to a new tube and mixed with Griess reagent. Then it was incubated for 10 minutes in the dark at room temperature. Finally, Griess2 reagent was added and the absorbance was measured spectro-photometrically at 540 $\mathrm{nm}[14]$.

\subsection{Determination of Antioxidant Activity of Thymus vulgaris}

Thyme extract and BHT stock solutions $(1.0 \mathrm{mg} / \mathrm{mL}$ in ethanol) were diluted to final concentrations of 20,40, 60,80 and $100 \mu \mathrm{g} / \mathrm{mL}$. $2 \mathrm{~mL}$ of DPPH solution (0.1 mM in ethanol) was added to BHT and thyme extract solutions at different concentrations and allowed to react at room temperature in dark. After 15 minutes the absorbance values were measured at $517 \mathrm{~nm}$ and converted into the percentage antioxidant activity using the following formula

$$
\mathrm{I}(\%)=100 \times\left(\mathrm{A}_{\text {control }}-\mathrm{A}_{\text {sample }}\right) / \mathrm{A}_{\text {control }}
$$

The antioxidant activity was expressed as IC50 (the concentration of extract required to inhibit the formation of DPPH radical by 50\%). The data was plotted by taking concentration on X-axis and percentage inhibition on Y-axis

\subsection{Determination of Total Phenolic Compounds}

Total phenolic compounds were determined using a modified version of the Folin-Ciocalteu method. $0.1 \mathrm{~mL}$ of diluted extract $\left(0.01 \mathrm{~g}\right.$ in $10 \mathrm{~mL}$ of $60^{\circ} \mathrm{C}$ methanol) was added to $0.5 \mathrm{~mL}$ of Folin-Ciocalteu reagent. After 5 minutes, $0.4 \mathrm{~mL}$ of $7.5 \%$ sodium carbonate was added to the mixture. The absorbance of colored solution was read after 30 minutes of incubation against reagent blank and distilled water. A standard curve was plotted using different concentrations of gallic acid. The absorbance of sample was compared with the standard curve and amount of phenols was obtained based on $\mathrm{mg} / \mathrm{g}$ in gallic acid equivalent [14]. 


\subsection{Determination of Total Flavonoid and Flavonol Contents}

The amount of total flavonoids in the Thymus vulgaris extract was determined using the colorimetric method. Briefly, $0.5 \mathrm{~mL}$ of thyme extract solution (0.01 $\mathrm{g}$ in $10 \mathrm{~mL}$ of $60^{\circ} \mathrm{C}$ methanol) was mixed with $1 \mathrm{~mL}$ of $2 \%$ aluminum chloride and $6 \mathrm{~mL}$ of $5 \%$ potassium acetate. The mixture was left at room temperature for 40 minutes. The absorbance of the reaction mixture was then measured at $415 \mathrm{~nm}$. The aluminum chloride colorimetric method was employed for flavonol determination, but the incubation period was 150 minutes and the absorbance of the reaction mixture was determined at $440 \mathrm{~nm}$. Total flavonoids and flavonols were expressed in terms of rutin equivalent ( $\mathrm{mg} / \mathrm{g}$ ), which is a common reference compound [14].

\subsection{Statistical Analysis}

One way- ANOVA followed by Tukey and t-paired tests were used for comparing the groups at 0.05 level of significance. All data were analyzed by using the statistical package for social sciences (SPSS-19) software and were summarized and expressed as mean and standard error (mean \pm SEM).

\section{Results}

\subsection{Passive Avoidance Test}

Comparison of the initial latency time (T1) in Figure 1 shows that the initial latency time was significantly longer in the ischemia group compared to the control group $(\mathrm{P}<$ $0.001)$. The initial latency time(T1) in the control group was also significantly shorter than the other groups $(\mathrm{P}<0.001)$. Results of passive avoidance test also showed that initial delay in all ischemic groups receiving Thymus vulgaris extract reduced compared with ischemic group, but this reduction was not significant.

According to our results, step through latency time to enter the dark room after induction of shock (T2), in the ischemic group was shorter than that in the control group however this was not significant. Administration of different doses of Thymus vulgaris extract into the ischemic groups, increased step through latency time compared to the ischemic group but this increase was not significant $(\mathrm{P}$ $=0.125$ ).

\subsection{Psychological Motor Coordination Tests}

In psychological motor coordination tests, our results revealed significantly higher balance in the control group compared with the ischemic group. Thymus vulgaris at doses of 100 and $200 \mathrm{mg} / \mathrm{kg}$ significantly improved balance compared to the ischemia group.

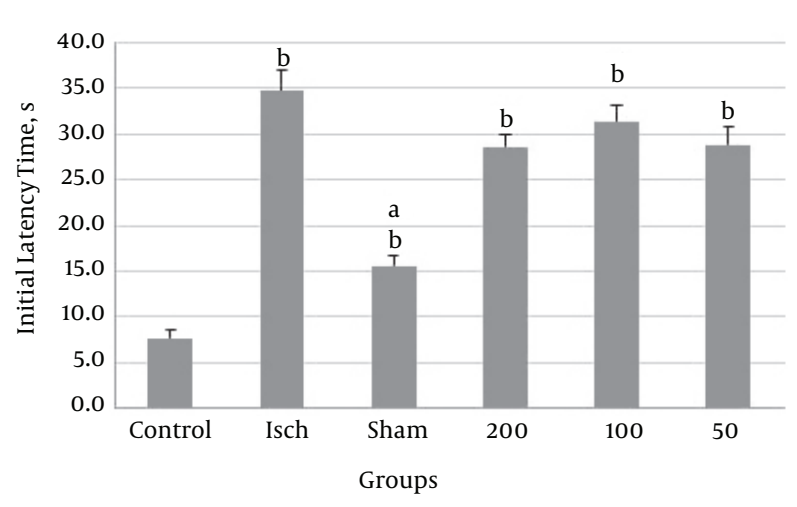

Figure 1. Comparison of Initial Latency Time (T1) Between Experimental Groups A Significant Differences Between Ischemic Group and Other Groups (Shame and Control Groups) B: Significant Differences Between Control Group and Other Groups

There was significant difference between ischemia group and other groups including control, sham and thyme extract $(100$ and $200 \mathrm{mg} / \mathrm{kg})$ treated group $(\mathrm{P}<$ 0.001 , Figure 3 ). There was also significant difference between control and other groups including ischemic, sham and thyme extract (50 and $100 \mathrm{mg} / \mathrm{kg}$ ) treated group $(\mathrm{P}<$ 0.001 , Figure 3). Thymus vulgaris extract at a dose of 50 $\mathrm{mg} / \mathrm{kg}$ had not any beneficial effect on balance Figure 2 .

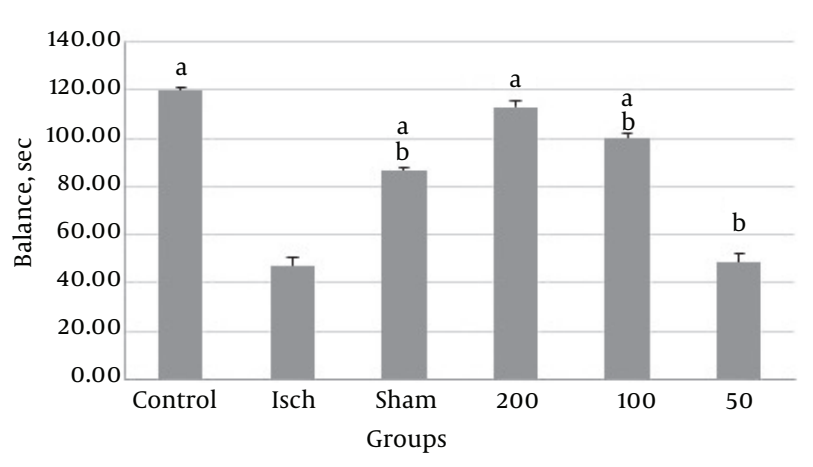

Figure 2. Comparison of Balance Between Experimental Groups a: Significant Difference Between Ischemia Group and Other Groups Including Control, Sham and Thyme Extract (100 and $200 \mathrm{mg} / \mathrm{kg}$ ) Treated B: Significant Difference Between Control and Other Groups Including Ischemic, Sham and Thyme Extract (50 and 100 $\mathrm{mg} / \mathrm{kg}$ ) Treated Group

\subsection{Brain and Plasma Antioxidant Capacity}

According to results administration of different doses of Thymus vulgaris extract in the ischemic groups increased antioxidant capacity of brain (hippocampus and cortex) and plasma compared to the ischemic group, but this increase was not significant $(\mathrm{P}>0.5)$. 


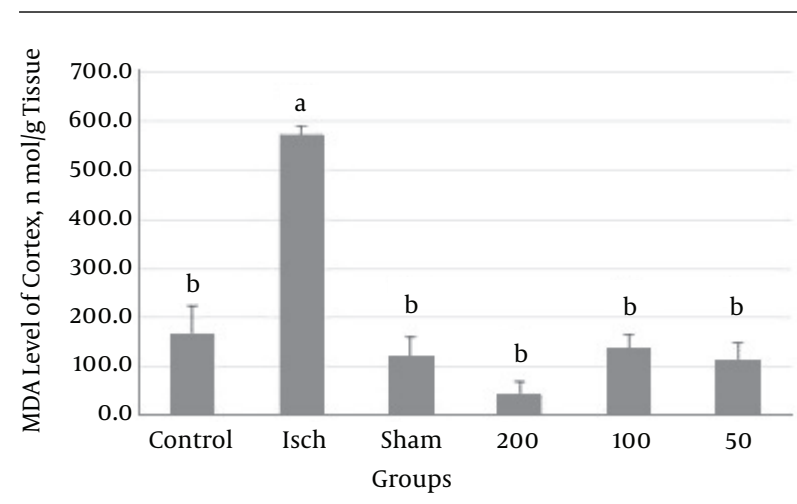

Figure 3. MDA Level of Cortex in the Experimental Groups A: Significant Difference Between Control and Ischemic Group B: Significant Difference Between Ischemic Group and Other Groups

\subsection{MDA Level of Brain}

In the present study, increase in the MDA activity of cortex was observed in ischemic group when compared with the control group $(\mathrm{P}<0.0001)$. According to Figure 3 , MDA levels of cortex were found to be increased in thyme extract treated groups in comparison with the ischemic group ( $\mathrm{P}$ $<0.0001)$.

\subsection{MDA Level of Plasma}

MDA levels of plasma in the ischemic group was significantly higher than that in the control group $(\mathrm{P}=0.003)$. Administration of Thymus vulgaris extract into the ischemic groups significantly decreased MDA levels of serum $(\mathrm{P}<$ 0.005) (Figure 4).

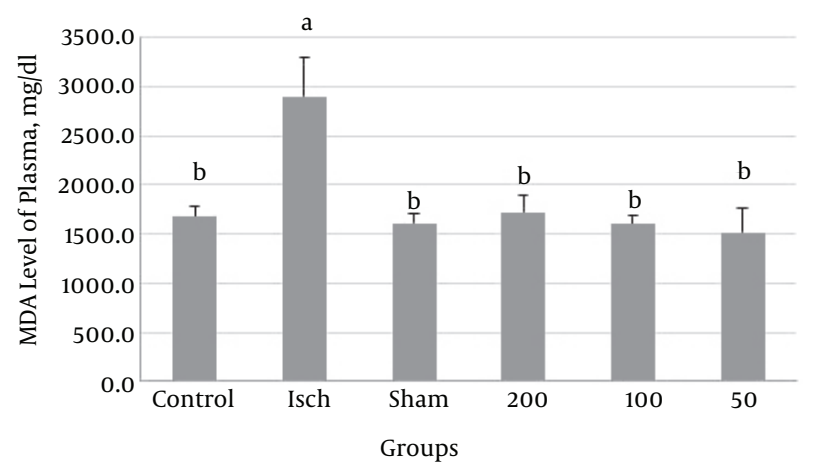

Figure 4. MDA Level of Plasma in the Experimental Groups A: Significant Difference Between Control and Ischemic Group B: Significant Difference Between Ischemic Group and Extract Treated Group

\subsection{Nitrate Level of Serum}

Serum nitrate level was higher in ischemic group than that in control group (not significant). Administration of thyme extract $(50,100$ and $200 \mathrm{mg} / \mathrm{kg})$ to ischemic groups reduced serum nitrate levels in comparison with the ischemia group, however, these reduction were not significant $(\mathrm{P}=0.184)$.

\subsection{Antioxidant Capacity of Thymus vulgaris Extract}

Table 1 shows the antioxidant capacity of thyme extract in DPPH method. The IC50 of thyme extract was 63.72 $\mu \mathrm{g} / \mathrm{mL}$.

Table 1. Antioxidant Capacity of Thymus vulgaris Extract

\begin{tabular}{|ll}
\hline Concentration, $\mu \mathbf{g} / \mathbf{m L}$ & $\begin{array}{l}\text { DPPH Radical Scavenging Activity Inhibition } \\
\text { IC50, \% }\end{array}$ \\
\hline 0 & 0 \\
\hline 10 & 9.4 \\
\hline 20 & 16.4 \\
\hline 30 & 23.4 \\
\hline 40 & 31.6 \\
\hline 50 & 39.6 \\
\hline 60 & 48.5 \\
\hline 70 & 56.9 \\
\hline 80 & 64.9 \\
\hline 90 & 70.94 \\
\hline 100 & 72.82 \\
\hline
\end{tabular}

3.8. Total Phenol, Flavonoids and Flavonol Contents of Thymus Vulgaris Extract

Total phenolic, flavonoid and flavonol contents of the Thymus vulgaris extracts were 290, 21.18 and $10.7 \mathrm{mg}$ respectively.

\section{Discussion}

In our study thyme extract treatment increased antioxidant capacity of brain (hippocampus and cortex) and plasma when compared with the ischemic group, moreover MDA levels in brain (hippocampus and cortex) and serum of extract treated rats were significantly lower than those in the ischemic group. We also observed that thyme extract decreased serum NO levels.

Stroke is one of the most important causes of death and disability of more than 75,000 individual annually. Stroke is the third leading cause of death in the United States after heart disease and cancer. Stroke may be responsible for persist long-term disability. According to the WHO estimates, 15 million people suffer stroke each year and about 5 million of them become permanently disabled. So 
stroke has a great economic and social burden to society. According to the statistics, one in every10 men and one in every 8 women die each year from stroke [20]. Ischemiareperfusion(IR) undergoes a process called oxidative stress which triggers ischemic injury.

Increase levels of reactive oxygen species (ROS) can increase lipid peroxidation and MDA level which lead to neural cell death $[21,22]$. During oxidation, endogenous and exogenous oxidants react with saturated fatty acids and produce peroxides which destroy myelin sheath, lipids, genetic material and other membrane components [23].

The hippocampus plays an important role in the formation of new memories and analysis of spatial data [24]. The hippocampus receives blood supply from the anterior choroidal artery, a branch of internal carotid. This artery is long and narrow which increases the risk of thrombosis. Hippocampus is one of the first brain areas to become damaged in the brain diseases such as Alzheimer's, Huntington, epilepsy, stroke, ischemic and traumatic brain injury [25]. Unilateral damage to the hippocampus may lead to subsequent amnesia but bilateral damage does not cause amnesia [26].

Specific types of neurons including pyramidal neurons in the CA1 region of hippocampal are extremely vulnerable to ischemia [27]. Destruction of CA1 pyramidal cells is the most important feature of ischemia which can lead to cognitive and behavioral defects such as memory impairment and hyperactivity disorder [28]. Results of behavioral testing showed that ischemia causes behavioral deficits. Time delay for entering into the dark room (after induction of shock) decreased in ischemic group compared with control group which shows animal inability to keep information. Administration of thyme extract (50, 100 and 200 $\mathrm{mg} / \mathrm{kg}$ ) into ischemic rats increased second latency time however this increase was not significant. Among these doses $200 \mathrm{mg} / \mathrm{kg}$ showed highest and $50 \mathrm{mg} / \mathrm{kg}$ showed lowest effect.

Comparison of balance between experimental groups showed that balance in the ischemia group was significantly lower than that in the control group. Moreover in all ischemic groups receiving thyme extract balance was higher than that in the control group.

Free radicals are an important therapeutic target in the treatment of ischemic complications. Antioxidant compounds such as polyphenols which are found in some foods have been shown to reduce ischemic damage in animal models [29]. Thyme tea has been shown to improve symptoms of neurological disorder and its use is recommended to all people with neurological disorders [30].

Kaledaite et al. (2011) investigate free radical scavenging activity of Thymus vulgaris and its effect on the ability of mitochondria to generate free radicals. Thyme extract showed strong antioxidant activity. Moreover liver mitochondria incubated with $0.1 \mathrm{mg}$ of extract generated lower radicals than control and mitochondria incubated with 1 mg of extracts generated smaller amounts of ROS than mitochondria incubated with $0.1 \mathrm{mg}$ of extract [31].

Koohi-Hosseinabadi et al. (2015) evaluated the histopathological changes in the four vital organs of diabetic and hyperlipidemic male rats after consumption of thyme extract. In their study brain lesions disappeared and declined after consumption of extract [32].

In Dursun et al. (2003) study treatment of rats with Thymus vulgaris extract decreased amount of nitric oxide produced after burn injury. They suggested that thyme extract may serve as a protective agent to the damaged tissues by decreasing the NO level [33]. Meeran et al. (2012) evaluates the protective effects of thymol (a main component of thyme oil) on plasma lipid peroxidation. They observed that treatment with thymol $(7.5 \mathrm{mg} / \mathrm{kg}$ body weight) normalizes levels of plasma lipid peroxidation products. They also confirmed potent antioxidant activity of thymol [34].

Komaki et al. (2016) studied effect of extract of Thymus vulgaris on anxiety in male rats. The results of the present experiment indicate that T. vulgaris may have an anxiolytic profile in rat behavior in the EPM (elevated plus-maze) test, which is not influenced by the locomotor activity [35].

Some researches indicated the fact that phenolic compounds were able to chelate metal ions. On the other hand, complexation of plant extracts with metal ions results in a significant reversal from antioxidant to pro-oxidant properties for the resulting complexes [36].

Even the drying methods of plants used for preparation of extracts could be responsible for the content of phenolics and flavonoids, as well as for the antioxidant activity of extracts and also their effects are dose dependent [37].

\subsection{Conclusion}

In conclusion, our results indicated that Thymus vulgaris extract has neuroprotective activity. It ameliorates oxidative stress and hippocampal neuronal damage after transient global cerebral ischemia in rat. Thymus vulgaris also increases antioxidant capacities of serum and brain and decreases MDA levels of them. Further investigations are needed to determine mechanisms of neuroprotective effects.

\section{Acknowledgments}

This work was supported by the Islamic Azad University of Izeh, Iran. Dr. Mahbubeh setorki gratefully acknowledge research funding from Izeh University (Grant number 156789). 


\section{Footnotes}

Authors' Contribution: All authors participated in the study, have read the manuscript, and provided their final approval. Mahbubeh Setorki studied design, collected and analyzed data. Sahar Mirzapoor preparated manuscript, and searched literature

Conflicts of Interests: The authors have no conflicts of interest to declare.

\section{Funding/Support: Islamic Azad University, Izeh Branch.}

\section{References}

1. Bonita R. Epidemiology of stroke. Lancet. 1992;339(8789):342-4. doi: 10.1016/0140-6736(92)91658-U. [PubMed:1346420].

2. Warner DS, Sheng H, Batinic-Haberle I. Oxidants, antioxidants and the ischemic brain. J Exp Biol. 2004;207(Pt 18):3221-31. doi: 10.1242/jeb.01022. [PubMed: 15299043].

3. Broughton BR, Reutens DC, Sobey CG. Apoptotic mechanisms after cerebral ischemia. Stroke. 2009;40(5):e331-9. doi: 10.1161/STROKEAHA.108.531632. [PubMed: 19182083].

4. Vannucci RC, Towfighi J, Vannucci SJ. Secondary energy failure after cerebral hypoxia-ischemia in the immature rat. J Cereb Blood Flow Metab. 2004;24(10):1090-7. doi: 10.1097/01.WCB.0000133250.03953.63. [PubMed: 15529009].

5. Cunningham LA, Wetzel M, Rosenberg GA. Multiple roles for MMPs and TIMPs in cerebral ischemia. Glia. 2005;50(4):329-39. doi: 10.1002/glia.20169. [PubMed: 15846802].

6. Shalak L, Perlman JM. Hypoxic-ischemic brain injury in the term infant-current concepts. Early Hum Dev. 2004;80(2):125-41. doi: 10.1016/j.earlhumdev.2004.06.003. [PubMed:15500993].

7. Lucas SM, Rothwell NJ, Gibson RM. The role of inflammation in CNS injury and disease. Br J Pharmacol. 2006;147 Suppl 1:S232-40. doi: 10.1038/sj.bjp.0706400. [PubMed: 16402109].

8. Swanson RA, Ying W, Kauppinen TM. Astrocyte influences on ischemic neuronal death. Curr Mol Med. 2004;4(2):193-205. doi: 10.2174/1566524043479185. [PubMed: 15032713].

9. Li J, Wang C, Zhang JH, Cai JM, Cao YP, Sun XJ. Hydrogen-rich saline improves memory function in a rat model of amyloid-betainduced Alzheimer's disease by reduction of oxidative stress. Brain Res. 2010;1328:152-61. doi: 10.1016/j.brainres.2010.02.046. [PubMed: 20171955].

10. Ikeda K, Negishi H, Yamori Y. Antioxidant nutrients and hypoxia/ischemia brain injury in rodents. Toxicology. 2003;189(12):55-61. doi: 10.1016/S0300-483X(03)00152-5. [PubMed: 12821282].

11. Murray MT, Pizzorno JE. Textbook of natural medicine. London: Churchill Living stone; 1999. pp. 270-2.

12. Thompson JD, Chalchat JC, Michet A, Linhart YB, Ehlers B. Qualitative and quantitative variation in monoterpene co-occurrence and composition in the essential oil of Thymus vulgaris chemotypes. J Chem Ecol. 2003;29(4):859-80. doi: 10.1023/A:1022927615442. [PubMed: 12775148].

13. Zargar A. Medicinal Plants. 4. Tehran University Press; 1988. pp. 28-38

14. Rabiei Z, Rafieian-Kopaei M, Heidarian E, Saghaei E, Mokhtari S. Effects of Zizyphus jujube extract on memory and learning impairment induced by bilateral electric lesions of the nucleus Basalis of Meynert in rat. Neurochem Res. 2014;39(2):353-60. doi: 10.1007/s11064-013-12328. [PubMed: 24379110].

15. Faraci FM. Protecting against vascular disease in brain. Am J Physiol Heart Circ Physiol. 2011;300(5):H1566-82. doi: 10.1152/ajpheart.01310.2010. [PubMed: 21335467].
16. Inage $\mathrm{YW}$, Itoh $\mathrm{M}$, Wada $\mathrm{K}$, Takashima S. Expression of two glutamate transporters, GLAST and EAAT4, in the human cerebellum: their correlation in development and neonatal hypoxic-ischemic damage. J Neuropathol Exp Neurol. 1998;57(6):554-62. doi: 10.1097/00005072199806000-00003. [PubMed: 9630235].

17. Moro MA, Cardenas A, Hurtado O, Leza JC, Lizasoain I. Role of nitric oxide after brain ischaemia. Cell Calcium. 2004;36(3-4):265-75. doi: 10.1016/j.ceca.2004.02.011. [PubMed: 15261482].

18. Gharib Naseri MK. Effect of Zataria multiflora Boiss leaf hydroalcoholic extract on rat ileum [In Persian]. J Kermanshah Univ Med Sci. 2003;7(3):18-26.

19. Rabiei Z, Rafieian M. Effects of Zizyphus jujuba extract on motor coordination impairment induced by bilateral electric lesions of the nucleus basalis of meynert in rat. Physiol Pharmacol. 2014;17(4):469-77.

20. Lakhan SE, Kirchgessner A, Hofer M. Inflammatory mechanisms in ischemic stroke: therapeutic approaches. J Transl Med. 2009;7:97. doi: 10.1186/1479-5876-7-97. [PubMed: 19919699].

21. Tug T, Karatas F, Terzi SM. Antioxidant vitamins (A, C and E) and malondialdehyde levels in acute exacerbation and stable periods of patients with chronic obstructive pulmonary disease. Clin Invest Med. 2004;27(3):123-8. [PubMed: 15305803].

22. Baluchnejadmojarad T, Roghani M. Effect of naringenin on intracerebroventricular streptozotocin-induced cognitive deficits in rat: a behavioral analysis. Pharmacology. 2006;78(4):193-7. doi: 10.1159/000096585. [PubMed: 17065836].

23. Thanonkaew A, Benjakul S, Visessanguan W, Decker EA. The effect of antioxidants on the quality changes of cuttlefish (Sepia pharaonis) muscle during frozen storage. Food Sci Technol. 2008;41(1):161-9. doi: 10.1016/j.lwt.2007.02.008.

24. Taupin P. The hippocampus: neurotransmission and plasticity in the nervous system. 1st ed. New York: Nova Publishers; 2007. pp. 20-5.

25. Eichenbaum H. Hippocampus: cognitive processes and neural representations that underlie declarative memory. Neuron. 2004;44(1):109-20. doi: 10.1016/j.neuron.2004.08.028. [PubMed: 15450164].

26. Guyton AC, Hall JE. Textbook of medical physiology. 11 ed. Elsevier Saunders; 2006.

27. Hassanshahi J, Hassanshahi GH,Zamani M, Hakimizadeh E, Soleimani M. Comparing the therapeutic effects of vitamin C and CoQ10 in reducing the number of damaged cells in mice hippocampus following ischemia-reperfusion [In Persian]. I Mazand Univ Med Sci. 2012;22(94):2-13.

28. Milot MR, Plamondon $\mathrm{H}$. Changes in HPA reactivity and noradrenergic functions regulate spatial memory impairments at delayed time intervals following cerebral ischemia. Horm Behav. 2011;59(4):594604. doi: 10.1016/j.yhbeh.2011.02.017. [PubMed: 21376725].

29. Mohagheghi F, Bigdeli MR, Rasoulian B, Zeinanloo AA, Khoshbaten A. Dietary virgin olive oil reduces blood brain barrier permeability, brain edema, and brain injury in rats subjected to ischemia-reperfusion. ScientificWorldJournal. 2010;10:1180-91. doi: 10.1100/tsw.2010.128. [PubMed: 20602077].

30. Mahmoudi B. Aromatic herbal essences and their therapeutic effects. Nure Danesh Advertisement. 2002:180-95.

31. Kaledaite R, Bernatoniene J, Majiene D, Dvorackova K, Masteikova R, Muselik J, et al. Investigation of antiradical activity of Salvia officinalis L., Urtica dioica L., and Thymus vulgaris L. extracts as potential candidates for a complex therapeutic preparation. J Med Plant Res. 2011;5(25):6090-6.

32. Koohi-Hosseinabadi O, Moini M, Safarpoor A, Derakhshanfar A, Sepehrimanesh $\mathrm{M}$. Effects of dietary Thymus vulgaris extract alone or with atorvastatin on the liver, kidney, heart, and brain histopathological features in diabetic and hyperlipidemic male rats. Comp Clin Path. 2015;24(6):1311-5. doi: 10.1007/s00580-015-2070-7.

33. Dursun N, Liman N, Ozyazgan I, Gunes I, Saraymen R. Role of thymus oil in burn wound healing. J Burn Care Rehabil. 2003;24(6):395-9. doi: 10.1097/01.BCR.0000095513.67541.0F. [PubMed:14610426]. 
34. Meeran MF, Prince PS. Protective effects of thymol on altered plasma lipid peroxidation and nonenzymic antioxidants in isoproterenol-induced myocardial infarcted rats. $J$ Biochem $\mathrm{Mol}$ Toxicol. 2012;26(9):368-73. doi: 10.1002/jbt.21431. [PubMed: 22890907].

35. Komaki A, Hoseini F, Shahidi S, Baharlouei N. Study of the effect of extract of Thymus vulgaris on anxiety in male rats. J Tradit Complement Med. 2016;6(3):257-61. doi: 10.1016/j.jtcme.2015.01.001. [PubMed: 27419090].

36. Yang UJ, Park TS, Shim SM. Protective effect of chlorophyllin and lycopene from water spinach extract on cytotoxicity and oxidative stress induced by heavy metals in human hepatoma cells. JToxicol Environ Health A. 2013;76(23):1307-15. doi: 10.1080/15287394.2013.851632. [PubMed: 24283422]

37. Hamrouni-Sellami I, Rahali FZ, Rebey IB, Bourgou S, Limam F, Marzouk B. Total phenolics, flavonoids, and antioxidant activity of sage (salvia officinalis 1.) plants as affected by different drying methods. Food Bioproc Tech. 2012;6(3):806-17. doi: 10.1007/s11947-012-0877-7. 